\title{
Side Slip of Wheels with Low and Ultra-low Profile Tires of a Personal Car negotiating a Turn
}

\author{
Stiliyana Taneva \\ Department of Transport and Aircraft Equipment and \\ Technologies \\ Technical University of Sofia, Plovdiv Branch \\ Plovdiv, Bulgaria \\ email s.taneva@tu-plovdiv.bg
}

\author{
Krasimir Ambarev \\ Department of Transport and Aircraft Equipment and \\ Technologies \\ Technical University of Sofia, Plovdiv Branch \\ Plovdiv, Bulgaria \\ email kambarev@tu-plovdiv.bg
}

\begin{abstract}
This article studies the influence of the speed of a car with low and ultra-low profile tires, 14" and 16", negotiating a turn through an interactive software system developed by us in the MATLAB environment. The changes of the normal and lateral loads of the wheels are obtained and the characteristics of the side slip angle (known as side slip) of the pneumatic tires are determined. Taking into account the side slip of the wheels, the software determines the center of the turn. The characteristics for the normal and lateral loads and of the side slip of the wheels for both types of tires are given. The influence of the tire profile on the handling characteristics is analysed. Recommendations are proposed for a personal car's motion in a turn with both types of tires.
\end{abstract}

Keywords - speed, side slip, load, turn, car, low and ultralow profile tires.

\section{INTRODUCTION}

The curvilinear motion of a vehicle is primarily associated with its stability and handling, and different models have been developed [1, 2, 3, 4, 5, 8, 9]. In a car's motion in a turn, a side slip of tires occurs under the action of lateral forces, which depends on various design and exploitation factors. In the developed models of a car's motion in a turn, the side slip is determined by a number of analytical models using experimental studies of tires [1, $2,3,4,5,7,8,9,11,12]$. The most commonly used is the "Magic formula" by H. B. Pacejka [3, 7, 11], which describes the behaviour of the pneumatic tire in a steady motion, but the formula has a large number of coefficients and their determination is sometimes associated with significant errors. Existing research does not always take into account the influence of the forward speed and the average angle of the steered wheels on the side slip for current values of the loads for low and ultra-low profile tires when driving a car in a turn.

The aim of this research is to study the influence of the forward speed of a car with low and ultra-low profile tires 14 " and 16 " in a turn, taking into account the redistribution of normal (vertical) load, and its effect on the characteristics of the side slip of the wheel tires. For this study the MATLAB environment interactive software system is developed.

\section{DETERMINING TIRE SIDE SLIP OF A CAR'S MOTION IN A TURN}

For the side slip of the tires of four wheels of a car negotiating a turn (Fig. 1) the following equations are used [6]:

- for the front axle

$$
\begin{gathered}
\delta_{1 v}=\theta_{v}^{\prime}-\operatorname{arctg} \frac{R_{\delta} \operatorname{tg}\left(\theta_{s r}-\delta_{1}\right)}{R_{\delta}-\frac{B_{1}}{2}}, \\
\delta_{1 v n}=\theta_{v n}^{\prime}-\operatorname{arctg} \frac{R_{\delta} \operatorname{tg}\left(\theta_{s r}-\delta_{1}\right)}{R_{\delta}+\frac{B_{1}}{2}}
\end{gathered}
$$

- for the rear axle 


$$
\delta_{2 v}=\operatorname{arctg} \frac{\operatorname{tg} \delta_{2}}{1-\frac{B_{2}}{2 R_{\delta}}}, \quad \delta_{2 v n}=\operatorname{arctg} \frac{\operatorname{tg} \delta_{2}}{1+\frac{B_{2}}{2 R_{\delta}}}
$$

where $B_{1}, B_{2}$ are respectively the track widths of the front and rear axles of the car; $\delta_{1 v}, \delta_{1 v n}$ are the tire slip angles, respectively of the inner and outer front wheel; $\delta_{2 v}, \delta_{2 v n}$ are the tire slip angles, respectively of the inner and outer rear wheel; $\theta_{v}, \theta_{v n}$ are the angles of rotation of the inner and outer wheel about the steering axis which is assumed to be equal to the steer angle of the inner and outer wheel in the ground plane $\theta_{v}^{\prime}, \theta_{v n}^{\prime \prime} ; R_{\delta}$ is the turning radius.

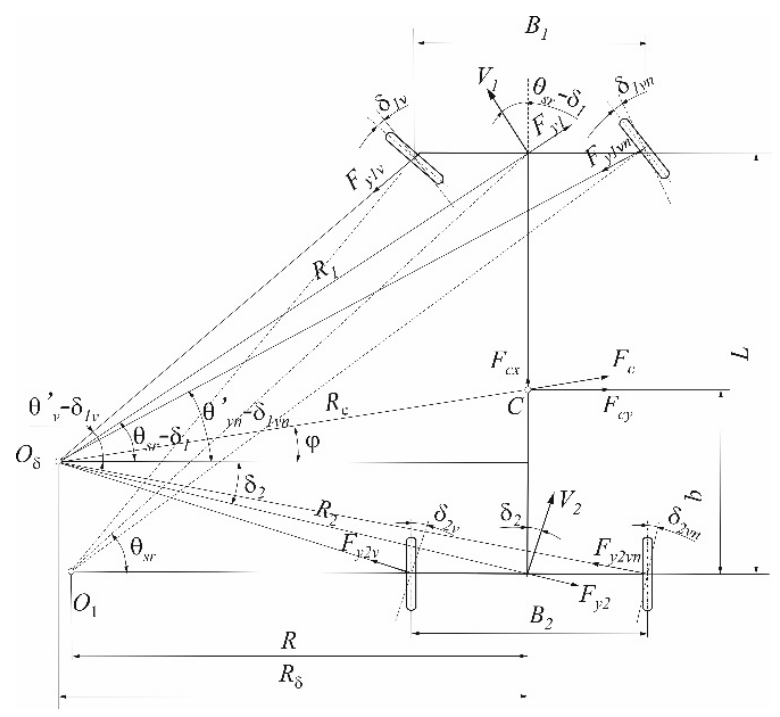

Fig. 1. Scheme of the side slip of tires of a car negotiating a turn [6].

To obtain the characteristics of the side slip of a car's tires, in [6] we propose these nonlinear dependencies

$$
\begin{gathered}
F_{y i}=k_{t} k_{r} \frac{\operatorname{arctg}\left[\pi k_{\delta 0 i} \delta_{i} /\left(2 \varphi_{y i} F_{z i}\right)\right]}{\pi /\left(2 \varphi_{y i} F_{z i}\right)} \\
F_{y i}=k_{t} k_{r} \frac{\operatorname{arctg}\left[\pi k_{\delta 0 i}\left(\delta_{i}-0,026\right) /\left(2 \varphi_{y i} F_{z i}\right)\right]}{\pi\left(\delta_{i}-0,026\right) /\left(2 \varphi_{y i} F_{z i}\right)} \delta_{i}
\end{gathered}
$$

where $k_{t}$ is the coefficient of the tire profile; $k_{r}$ is the coefficient of the rim dimensions; $F_{z i}$ is the load on the $i^{\text {th }}$ wheel in $\mathrm{N} ; k_{\delta 0 i}$ is the cornering stiffness of the tires of the $i^{\text {th }}$ wheel; $\varphi_{y i}$ - the coefficient of lateral grip of $i^{\text {th }}$ wheel.

The coefficients used above take into account the change in the tire profile and the normal load, and are explained in detail in [10].

Taking into account the basic parameters of the car, the normal, lateral and longitudinal reactions (forces) of the wheels in a car's motion in a turn can be defined by taking into account their grip with the road surface.
Normal reactions on the car's wheels are determined by taking into account the redistribution of the normal load between the front and rear axles. The outer wheels are additionally loaded, while the inner wheels are unloaded. For the normal loads of the inner and outer wheels, based on Fig. 1, the following equations apply [6]:

- for the front axle

$$
\begin{aligned}
& F_{z 1 v}=\frac{G \cdot b}{2 L}+A \frac{\cos ^{2} \delta_{2}}{R_{\delta}^{2}}-A \frac{\sin 2 \delta_{2}}{2 \cdot b \cdot R_{\delta}}-B \frac{\cos ^{2} \delta_{2}}{R_{\delta}}, \\
& F_{z 1 v n}=\frac{G \cdot b}{2 L}+A \frac{\cos ^{2} \delta_{2}}{R_{\delta}^{2}}-A \frac{\sin 2 \delta_{2}}{2 \cdot b \cdot R_{\delta}}+B \frac{\cos ^{2} \delta_{2}}{R_{\delta}}
\end{aligned}
$$

- for the rear axle

$$
\begin{aligned}
& F_{z 2 v}=\frac{G(L-b)}{2 L}-A \frac{\cos ^{2} \delta_{2}}{R_{\delta}^{2}}+A \frac{\sin 2 \delta_{2}}{2 b R_{\delta}}- \\
& -C \frac{\cos ^{2} \delta_{2}}{R_{\delta}}, \\
& F_{z 2 v n}=\frac{G(L-b)}{2 L}-A \frac{\cos ^{2} \delta_{2}}{R_{\delta}^{2}}+A \frac{\sin 2 \delta_{2}}{2 b R_{\delta}}+ \\
& +C \frac{\cos ^{2} \delta_{2}}{R_{\delta}}
\end{aligned}
$$

and coefficients A, B and C are determined according to [6].

On Fig. 1, for the inner and outer wheel lateral forces, the following equations apply:

- for the front axle

$$
\begin{aligned}
& F_{y 1 v}=F_{y 1} \frac{\sin \left[\left(\theta_{s r}-\theta_{v n}^{\prime}\right)+\left(\delta_{1 v n}-\delta_{1}\right)\right]}{\sin \left[\left(\theta_{v}^{\prime}-\theta_{v n}^{\prime}\right)+\left(\delta_{1 v n}-\delta_{1 v}\right)\right]}, \\
& F_{y 1 v n}=F_{y 1} \frac{\sin \left[\left(\theta_{v}^{\prime}-\theta_{s r}\right)+\left(\delta_{1}-\delta_{1 v}\right)\right]}{\sin \left[\left(\theta_{v}^{\prime}-\theta_{v n}^{\prime}\right)+\left(\delta_{1 v n}-\delta_{1 v}\right)\right]}
\end{aligned}
$$

- for the rear axle

$$
\begin{aligned}
& F_{y 2 v}=F_{y 2} \frac{\sin \left(\delta_{2 v}-\delta_{2}\right)}{\sin \left[\left(\delta_{2}-\delta_{2 v n}\right)+\left(\delta_{2 v}-\delta_{2}\right)\right]}, \\
& F_{y 2 v n}=F_{y 2} \frac{\sin \left(\delta_{2}-\delta_{2 v n}\right)}{\sin \left[\left(\delta_{2}-\delta_{2 v n}\right)+\left(\delta_{2 v}-\delta_{2}\right)\right]}
\end{aligned}
$$

where $F_{y 1}$ and $F_{y 2}$ are the total lateral forces acting on the front and rear axle, and they are defined by the centrifugal force and transforming trigonometric equations for the vector triangles of forces [6]. 
Environment. Technology. Resources. Rezekne, Latvia Proceedings of the $13^{\text {th }}$ International Scientific and Practical Conference. Volume 3, 336-342

An iterative method with the system proposed in [6] is used to determine the center of the turn, the reactions of the road surface on the wheels, and the slip angles of a car's motion in a settled turn with low and ultra-low profile tires. The side slip of wheels at a different car's forward speeds is also defined.

Initially, the minimum steer angles of the steered wheels $\left(\theta_{v}^{\prime}, \theta_{v n}^{\prime}\right)$ are set and the average slip angle of the steered wheels is calculated. For each value of $\theta_{s r}$ and at different speed of the car, the side slip of the front $\delta_{1}$ and rear axle $\delta_{2}$ is defined by specifying the centre of the turn $\mathrm{O}_{\delta}$ (Fig. 1) iteratively.

With the equations proposed in $[6,10]$ and the K.Enke Method further developed by us [6] the non-linear characteristics of the side slip of the wheels $F_{y i}=f\left(\delta_{i}\right)$ for the corresponding normal load on each wheel are defined for the front and rear axle. The characteristics of the side slip are derived while defining the cornering stiffness by the averaged experimental curves defined by us in [10] for: the referred length of contact patch $a_{p r}$, angular stiffness $c_{\omega}^{\prime \prime}$ and coefficient of lateral grip $\varphi_{y}^{\prime \prime}$ for low and ultra-low profile tires with rim dimensions from 13 ” to 16 ” . The cornering stiffness is calculated by the equation $k_{\delta 0 i}=2 c_{\omega}^{\prime \prime} / a_{p r}^{\prime \prime}$, and the coefficient of lateral grip - $\varphi_{y i}=k_{\varphi y}^{\prime \prime} \varphi_{y}[10]$.

In this research lateral forces are defined by the Enke Method, but this can be also done by the equations (7) and (8).

The study is carried out according to the flowchart in Fig. 2. The full version of the software algorithm is presented in [6].

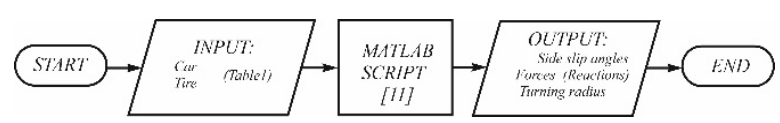

Fig. 2. Software flowchart.

\section{RESULTS AND DISCUSSION}

The object of study was a Honda Civic Aerodeck personal car with the parameters given in table 1, with two tire dimensions, respectively 185/60R14 and 205/40R16. The second tire dimensions are proposed by the car manufacturer as an alternative, while preserving the rolling radius of wheels. According to Table 1 , the rolling radius $r_{k} \approx 0,285 \mathrm{~m}$.
TABLE 1 CAR AND TIRE CHARACTERISTICS.

\begin{tabular}{|c|c|c|}
\hline Parameter, [unit] & Designation & Value \\
\hline \multicolumn{3}{|l|}{ Car } \\
\hline Total mass [kg] & $\mathrm{m}$ & 1665 \\
\hline Front axle track width [m] & $\mathrm{B}_{1}$ & 1,475 \\
\hline Rear axle track width [m] & $\mathrm{B}_{2}$ & 1,475 \\
\hline Wheelbase [m] & $\mathrm{L}$ & 2,62 \\
\hline Maximum inner steer angle $\left[{ }^{0}\right]$ & $\theta_{\mathrm{v}}$ & 36 \\
\hline Maximum outer steer angle $\left[{ }^{0}\right]$ & $\theta_{\mathrm{vn}}$ & 30 \\
\hline $\begin{array}{l}\text { Distance between rear axle and the } \\
\text { center of gravity (figure } 1 \text { ) [m] }\end{array}$ & $\mathrm{b}$ & 1,286 \\
\hline Height of the center of gravity [m] & $\mathrm{h}$ & 0,50 \\
\hline Maximum speed [km/h] & $\mathrm{V}$ & 191 \\
\hline \multicolumn{3}{|l|}{ Tires } \\
\hline \multicolumn{3}{|l|}{ Dimensions 185/60R14 } \\
\hline Width [mm] & $\mathrm{B}_{\mathrm{t}}$ & 185 \\
\hline Height [mm] & $\mathrm{H}_{\mathrm{t}}$ & 111 \\
\hline Rim diameter [mm] & $\mathrm{d}_{\mathrm{r}}$ & 355,6 \\
\hline \multicolumn{3}{|l|}{ Dimensions 205/40R16 } \\
\hline Width [mm] & $\mathrm{B}_{\mathrm{t}}$ & 205 \\
\hline Height [mm] & $\mathrm{H}_{\mathrm{t}}$ & 82 \\
\hline Rim diameter [mm] & $d_{r}$ & 406,4 \\
\hline Air pressure $[\mathrm{MPa}]$ & $\mathrm{p}_{a}$ & 0,25 \\
\hline
\end{tabular}

3.1. Results for the side slip, the lateral and normal load on the wheels and the car's turning radius with the two tire dimensions at forward speed of 20, 50 and $110 \mathrm{~km} / \mathrm{h}$

- for forward speed of $20 \mathrm{~km} / \mathrm{h}$

Fig. 3 shows the variation of the side slip of the front and rear axle with average steer angle in the plane of the road surface, and Fig. 4 - the variation of the side slip of the inner and outer wheels of the front and rear axle with average steer angle in the plane of the road surface, for the respective speed.

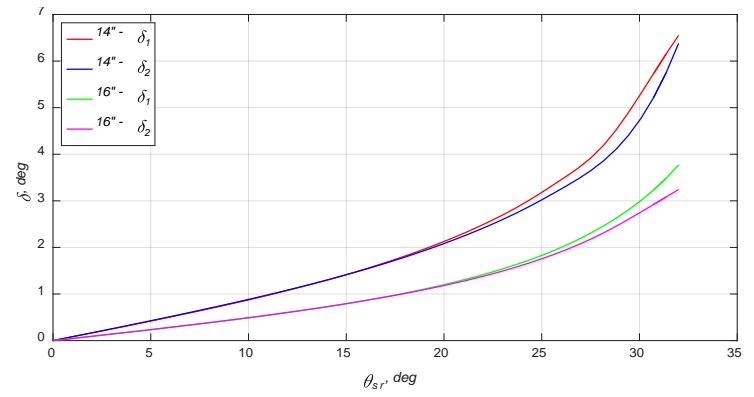

Fig. 3. Characteristics of the side slip of the front and rear axles. 


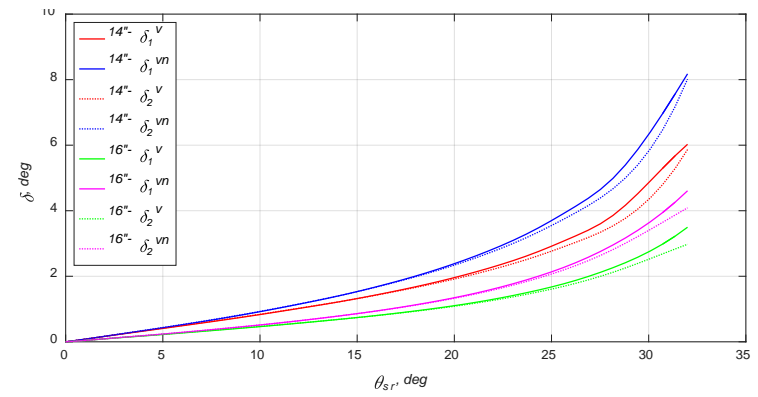

Fig. 4. Characteristics of the side slip of the tires.

Fig. 5 and Fig. 6 show the variation of the lateral and normal loads with average steer angle respectively and Fig. 7 - the variation in the turning radius with average steer angle.

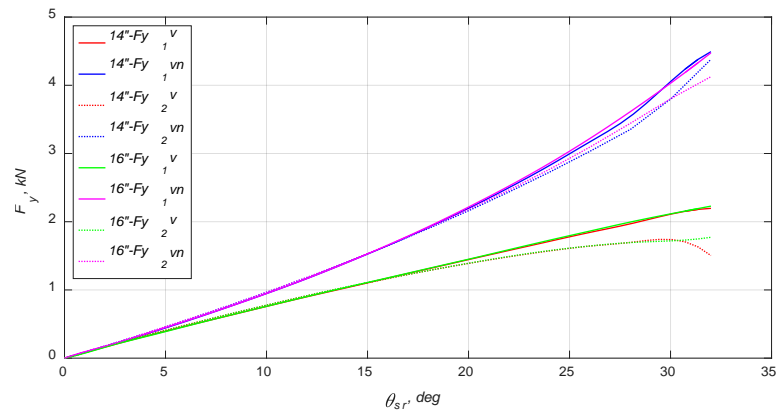

Fig. 5. The lateral loads of the wheels.

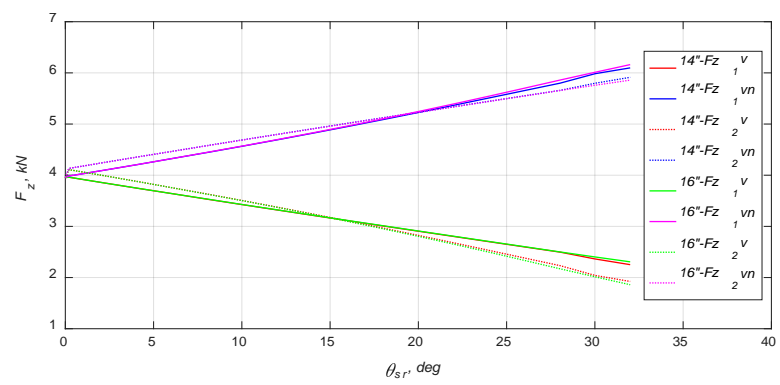

Fig. 6. The normal loads of the wheels.

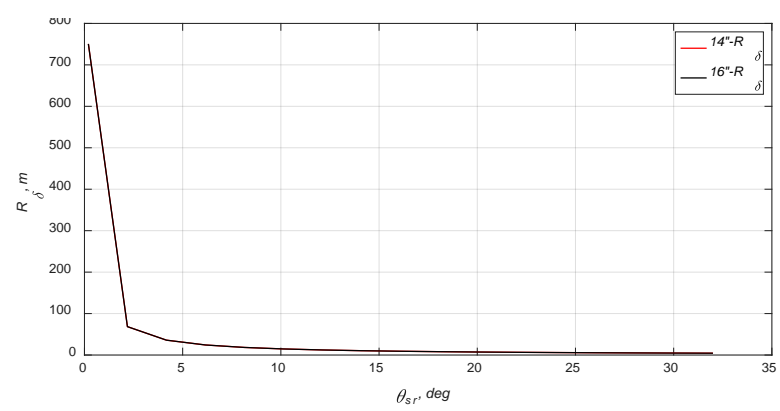

Fig. 7. The turning radius.

- for forward speed of $50 \mathrm{~km} / \mathrm{h}$

Fig. 8 presents the side slip of the front and rear axles and Fig. 9 shows the side slip of the four wheels of the car. Fig. 10 and Fig. 11, respectively, present the lateral and normal loads on the wheels, and Fig. 12 - the turning radius.

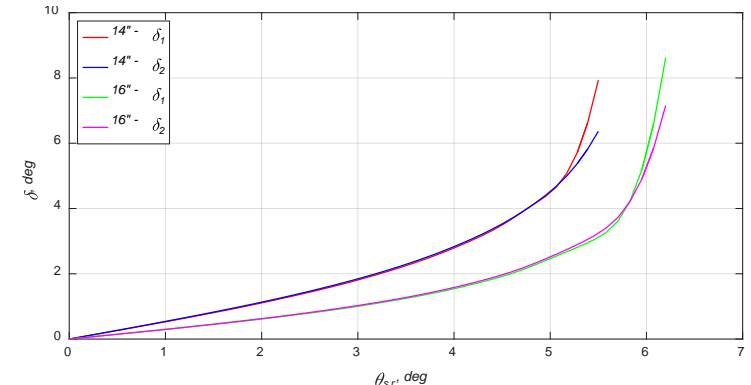

Fig. 8. Characteristics of the side slip of the front and rear axles.

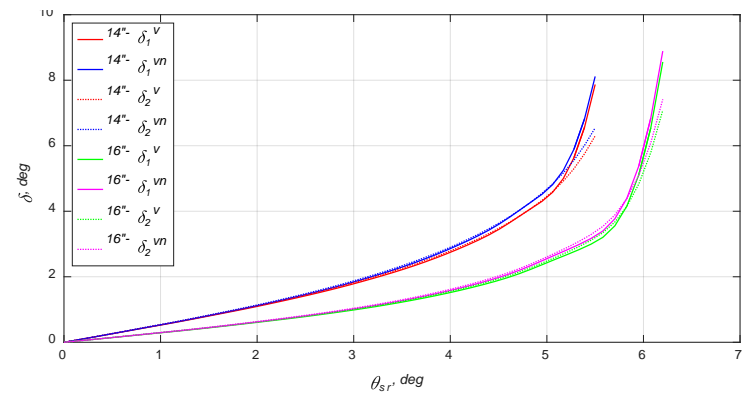

Fig. 9. Characteristics of the side slip of the tires.

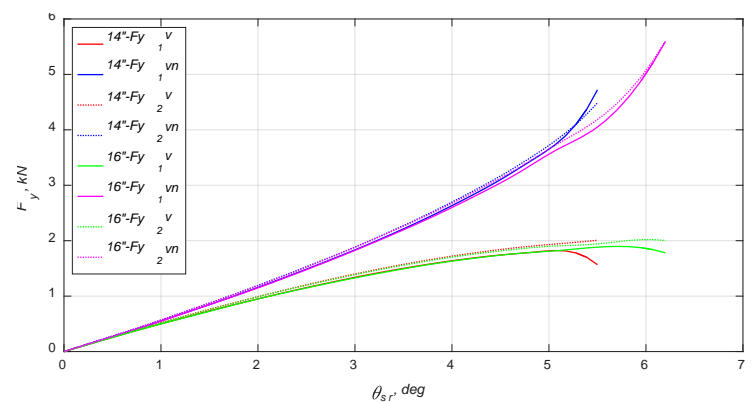

Fig. 10. The lateral loads of the wheels.

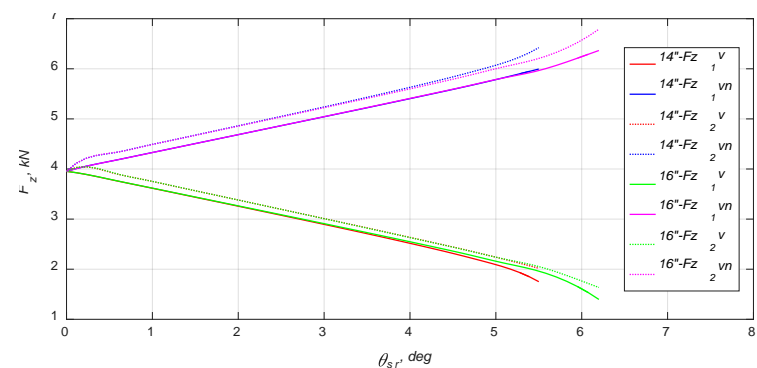

Fig. 11. The normal loads of the wheels.

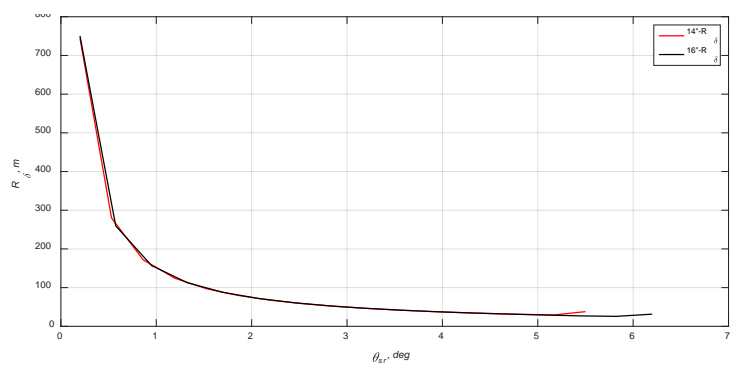

Fig. 12. The turning radius. 
Environment. Technology. Resources. Rezekne, Latvia Proceedings of the $13^{\text {th }}$ International Scientific and Practical Conference. Volume 3, 336-342

- $\quad$ for forward speed of $110 \mathrm{~km} / \mathrm{h}$

Fig. 13 presents the side slip of the front and rear axles and Fig. 14 shows the side slip of the four wheels of the car. Fig. 15 and Fig. 16, respectively, present the lateral and normal loads on the wheels, and Fig. 17 - the turning radius.

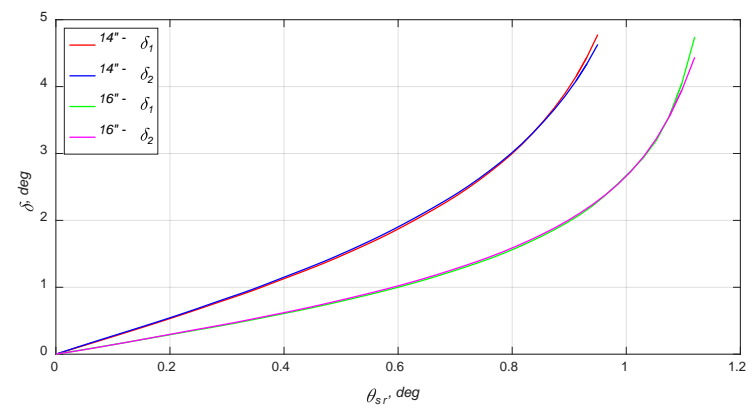

Fig. 13. Characteristics of the side slip of the front and rear axles.

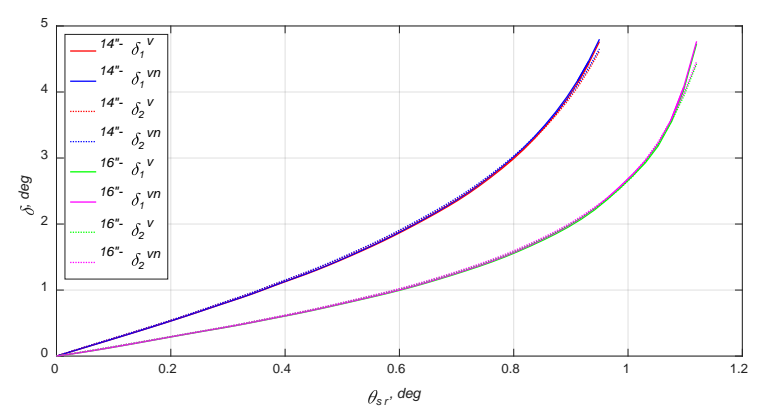

Fig. 14. Characteristics of the side slip of the tires.

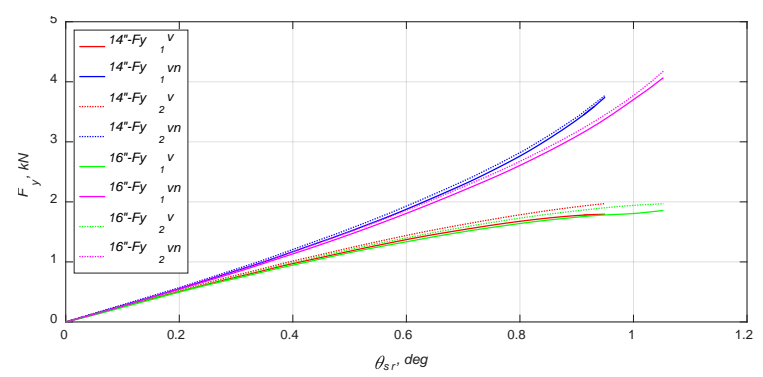

Fig. 15. The lateral loads of the wheels.

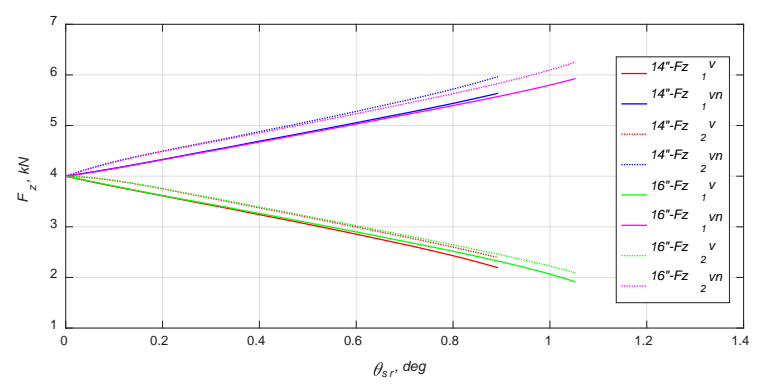

Fig. 16. The normal loads of the wheels.

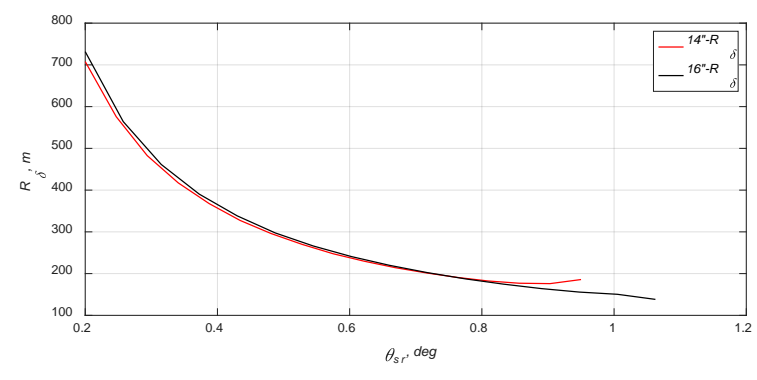

Fig. 17. The turning radius.

The analysis of the figures (from Fig. 3 to Fig. 17) shows that the car with ultra-low profile tires with dimensions 205/40R16 has a significantly lower value of side slip and also has a tendency to understeer $\delta_{1}>\delta_{2}$. The outer wheels have greater side slip with regard to the turn, which is due to the change in their side slip characteristics due to the increased load. The lateral and normal loads on the inner wheels decrease and at a certain speed, the car loses stability and handling. When the speed increases, the turning radius decreases as the steer angle is changed. For the ultra-low profile tires, the steer angle increases.

\subsection{Three-dimensional graphs of the variation in the side slip for the entire range of the car's forward speed}

The study presented above is for stepwise change of speed of a car's motion in a turn (20, 50 and $110 \mathrm{~km} / \mathrm{h})$, which gives very good results for side slip, but threedimensional graphics provide a clearer idea for the entire range of speed variation $\delta=f\left(\theta_{s r}, V\right)$.

The side slip of the two axles and of the tires for the entire range of the car's speed from 0 to $191 \mathrm{~km} / \mathrm{h}$, for both tire dimensions, is presented on Fig. 18 and Fig. 19.

Fig. $18 a$ and Fig. $18 b$ present the side slip of the front axle and Fig. $18 c$ and Fig. $18 d$ - of the rear axle for the two tire dimensions.

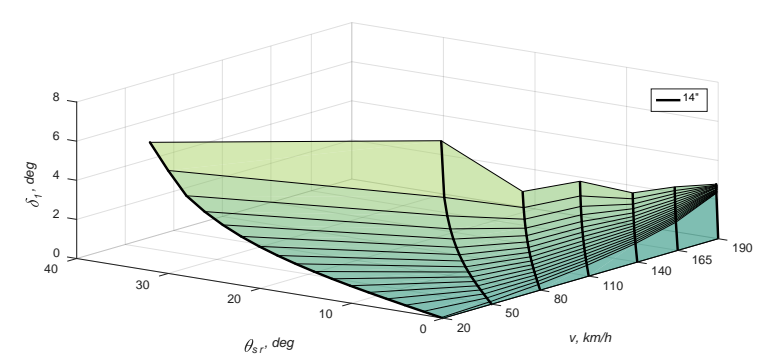

a) Tire “185/60 R14” 


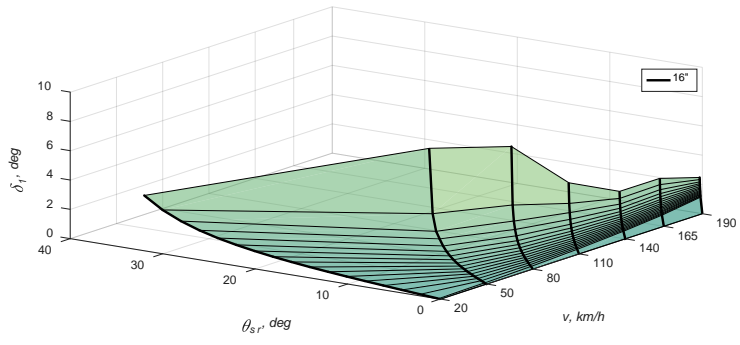

b) Tire “205/40 R16”

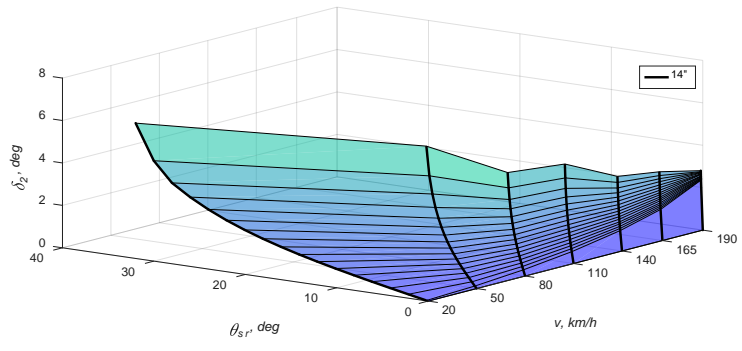

c) Tire “185/60 R14”

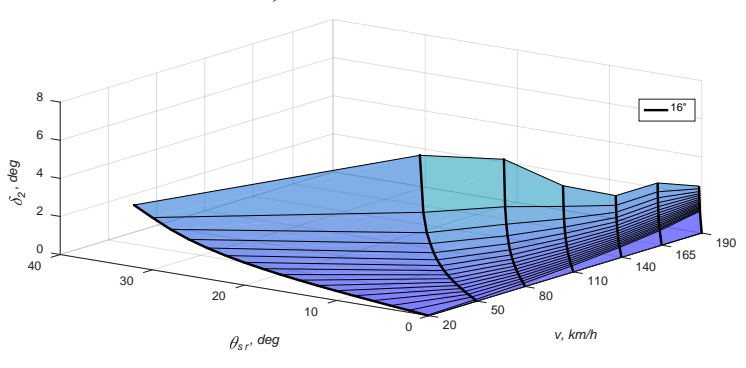

d) Tire "205/40 R16"

Fig. 18. Influence of the average angle of the steered wheels and the forward speed on the side slip.

Fig. $19 a$ and Fig. $19 b$ present the side slip of the most loaded front outer wheel for the two tire dimensions.

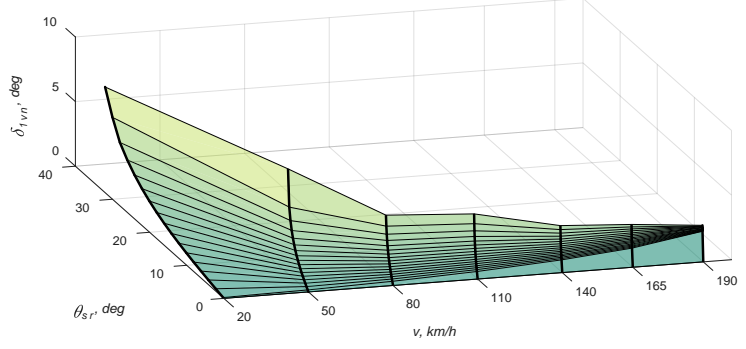

a) Tire “185/60 R14”

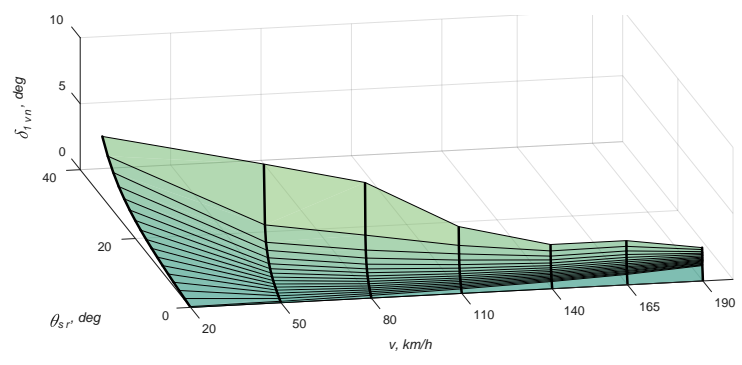

b) Tire “205/40 R16”

Fig. 19. Influence of the average angle of the steered wheels and the forward speed on the side slip.
The analysis of the data presented at the threedimensional graphs gives a clear idea of the change of the wheels' side slip, and the data in 3.1 for the different speeds agrees completely. On the basis of the presented three-dimensional graphs, the side slip of the car's motion at all speeds can be analyzed.

\section{CONCLUSIONS}

The study allows to make the follow conclusions:

- The proposed interactive software system in the MATLAB environment using the advanced Enke Method allows the determination of the lateral forces by the changing characteristics of the side slip of tires at constant values of the normal loads.

- As the turning radius decreases, the grip of the inner wheels decreases.

- The handling and stability of personal car during a turn at high speeds shall be improved by replacing lowprofile tires with alternative ultra-low profile tires permitted by the vehicle design when motion on asphalt or concrete road, while preserving the rolling radius of the wheels.

- The three-dimensional graphics show that as the forward speed and the average steer angle increase the side slip of the tires decreases.

\section{ACKNOWLEDGMENTS}

This work was supported by the European Regional Development Fund within the OP "Science and Education for Smart Growth 2014-2020”, Project Competence Centre "Smart Mechatronic, Eco-And Energy Saving Systems And Technologies”, № BG05M2OP001-1.0020023.

\section{REFERENCES}

[1] D. A. Antonov, Theory of stability of vehicle motion, Moscow, Mechanical Engineering, 1978

[2] A.S. Litvinov, Handling and stability of the vehicle, Moscow, Mechanical Engineering, 1971.

[3] H. B. Pacejka, Tyre and Vehicle Dynamics, Second edition, Amsterdam, Boston, Heidelberg, London, New York, Oxford, Paris, San Diego, San Francisco, Singapore, Sydney, Tokyo, ISBN -13: 980-0-7506-6918-4, 2006.

[4] G. Rill, Road vehicle dynamics: Fundamental and Modeling, Taylor \& Francis Group, LLC, ISBN - 13: 978-1-4398-9744-7, 2012.

[5] J. Y. Wong, Theory of ground vehicles, Third edition, New York, ISBN 0-471-35461-9, 2001.

[6] S. Taneva, K. Ambarev, D. Katsov, Interactive system for study of car's movement with low and ultra-low profile tires in a turn, Proceedings of the $12^{\text {th }}$ International Scientific and Practical Conference, Environment. Technology. Resources. Rezekne, Latvia, pp. 224-228, 2019.

[7] E. Bakker, L. Nyborn, H. Pacejka, Tyre Modelling for Use in Vehicle Dynamics Studies, SAE International Journal, Paper № 870421, Vol. 2, pp. 190-204, 1987.

[8] D. A. Katsov, D. A. Hlebarski, Dynamics of the turn of wheel vehicle with account of the deformations of the tires and the influence of the suspension, International Journal of Computational and Numerical Analysis and Applications, Vol. 6, No. 2, pp.97106, 2004.

[9] D. A. Katsov, D. A. Hlebarski, Kinematics of the turn of wheel vehicle with account of the deformations of the tires and the 
Environment. Technology. Resources. Rezekne, Latvia Proceedings of the $13^{\text {th }}$ International Scientific and Practical Conference. Volume 3, 336-342

influence of the suspension, International Journal of Computational and Numerical Analysis and Applications, Vol. 25, No. 2, pp. 203214, 2005.

[10] D. Katsov, S. Taneva, Investigation of the lateral slip and grip of low and superlow profile tires of cars, Journal of Machine Building and Machine Science, Varna, Bulgaria, Year. X, No. 2, Vol. 24, pp. 39-45, 2015.
[11] H. Pacejka, E. Bakker, The Magic Formula Tyre Model, International Journal of Vehicle Mechanics and Mobility, Suppl. Vehicle System Dynamics, Vol. 21, pp. 1-18, 1992.

[12] L. Palkovics, M. El-Gingy, Neural Network Representation of Tyre Characteristics: The Neuro-Tyre, International Journal of Vehicle Design, Vol.14, pp. 563-591, 1993. 